\title{
Dynamics of Female Buying Behaviour: A Study of Branded Apparels in India
}

\author{
Namita Rajput ${ }^{1}$, Subodh Kesharwani ${ }^{2}$ \& Akanksha Khanna ${ }^{2}$ \\ ${ }^{1}$ Department of Commerce, Sri Aurobindo College, University of Delhi, Delhi, India \\ ${ }^{2}$ School of Management Studies, Indira Gandhi National Open University, Delhi, India \\ Correspondence: Namita Rajput, Department of Commerce, Sri Aurobindo College, University of Delhi, Delhi \\ 110054, India. E-mail: namitarajput27@gmail.com
}

Received: March 3, 2012 Accepted: May 16, 2012 Online Published: July 25, 2012

doi:10.5539/ijms.v4n4p121 URL: http://dx.doi.org/10.5539/ijms.v4n4p121

\begin{abstract}
Consumer market for fashion apparel has become more varied by in surge of designer brands, store brands, personalisation, customs and advertisement in the global market place of today. A clear understanding of preferences of consumers will help the marketer to attract and maintain their target consumer group. The purpose of this study is to examine Indian female consumers buying behaviour and deeply understand the key factors of branded clothing which influence female consumers' involvement towards stylish branded clothing. It was found in the study that there is a complete awareness of the branded apparels amongst females and their shopping behaviour reflect that they buy these products occasionally. Females have particular perspectives and motives behind their purchases. The culture is shifting towards buying from the malls because of shopping experience the consumers get. The most important source of information was found to be family and friends followed by internet and advertisement. It is observed in the study that Price, Fitting, Income Level of consumers are significant factors and some factors which are found to be insignificant are Status, Durability, and celebrity endorsement, hence can be ignored by the apparel retailers in their efforts to tap and capture the market. As a retailer of apparels, all these insights have to be embedded in the policy formulation to make the purchases a real time customer delight.
\end{abstract}

Keywords: fashion brands, consumer behaviour, female consumer, apparel market, celebrity endorsement

\section{Introducation}

Products communicate different connotation to different people. The current urban middle and upper class Indian consumer buying behavior to a large extent has the Western influence especially amongst females. There is an increase in positive attitude towards the Western trends. The Indian consumer has become much more open-minded and experimental in their perspective. Foreign brands have gained wide consumer acceptance in India.Fashion is a billion-dollar industry employing millions of people not only in emerging economies but across the globe. By this changing landscape consumers are affected to a large extent by theses swift changes. Towards the late 1980's, dominance of few large retailers and structural changes were seen in the apparel Industry. Over the past decades the fashion industry has gone through some major structural changes. In the fast evolving fashion industry even the best plans and activities can be undermined by economic change and the actions of competitors. There is a clear understanding amongst retailers on the issue that a complete perceptive view of the target consumers is very helpful in ornamenting shopping propensity. Most choice contours and shopping behaviour tends to simplify and generalize the view but are full of paucities in augmenting the information which is useful in positioning and segmenting the market. Although the apparel industry seems to be in the maturity stage and growth is slow, fashion trend cycles are accelerating - nowadays the average successful clothing trend lasts for a short span of time i.e. Six to twelve weeks hence to gain from the situation is all the more difficult and challenging in nature. There has been an unprecedented trend of presence of more and more brands because of which there is a competitive environment which was unheard of in the past (Rutter \& Edwards, 1999). There is a noteworthy trend of females emerging as a major change and is considered to be the most important consumer, mainly because they have joined the labour market and there is a major rise in their disposable income (Schiffman \& Kanuk in Shim \& Kotsiopulos, 1993). Consequently they are recognised by apparel marketers as a major sought after target market (Cassill \& Drake, 1987). 
Brand management holds the key in the modern markets, particularly in Indian markets because Indians are very traditional. India's traditional dress for women is sari but gradually, it was transmitted into tailor made dresses. Due to the globalization process, Indians are getting attracted to readymade western dresses, particularly Multinational brands. The growth of readymade women's wear business in India was very slow till the early -1980 's. The main reason for this was that Indian women were used to buying clothing and getting their outfits tailored mainly through local tailoring shops from the unorganized segment as a result of which there were no national level brands in this category for a very long period of time. By the mid 1980's however customer mindset seemed to have started changing gradually, along with increasing urbanization, and changes in the social and economic status and life styles. As in many other industries in the nation, the move towards 'branding' soon took momentum in the women's wear market.

Regarding female garments, it is today easy to buy high fashion at a low price, particularly regarding female garments. It is majorly seen that women view shopping as a fun, satisfying, hedonic and joyful activity. The female attitude towards shopping seems very positive and they look forward to this communal event with cheerful prospects. Clothing is an important part and parcel of women's life and plays an imperative role in building the identity of the women. The very important tool which is used by women to strengthen her self esteem is clothes. All important experiences of women while shopping and its importance create a constant demand for clothes which gives this market a great potential for growth. There are many factors which impact the buying behaviour of females like organised retail stores, malls, fit, look, style, rising income, rising young consumer base and multiple brands available in the market.

In the world of today there are plenty of gender based differences which are observed by the marketers in almost all the products like food, drinks, apparels etc. Some which are available in the market are having feminine or masculine attribute, for example most pink possessions are regarded as feminine while blue and darker colours stuff are considered for males exclusively. There is a huge difference in their perception, mindset in their buying behaviour with men giving importance to luxury and leisure items for example music systems, video games with more of rational appeal in their buying behaviour etc where as females are normally into the buying of the products which are related to self expression that will make them look good like hand bags, shoes, dresses and gifts etc and the content and use of emotional appeal is more which influence their buying decisions.

The objective of this paper is to gain insights of female consumer behaviour. This information will be imperative in strategy formulation and gain from the situation which is instrumental in increasing the turnover. This segment of society is very important group amongst all the groups in the society because major purchases in the family, is either done for her own use as a consumer and rest of them for the family as a customer. This makes it all the more important to understand her psychology, her mind set, her motivators, satisfiers and dissatisfiers.

\section{Review of Literature}

Gender can be explained with the terms gender distinctiveness and the role it plays. Gender identity can be explained as to which degree a man or a woman identifies with masculine and feminine behaviour traits. Gender differences refer to difference in their responsibilities, roles, and privileges of men and women , this makes them different and they respond to all stimuli and products offered by the marketer differently (Fischer \& Arnold, 1994). Demographics \& household structures, desires, emotions, ethics and personality, group influences, information processing are considered some of the key factors responsible for buying purchase behaviour. Consumer's purchases are sturdily influenced by the factors like cultural, social, personal and psychological characteristics were reported by Thomson, \& Locander (1994). The marketers find it very difficult to formulate a different strategy for both males and females. There is no economic viability also to formulate strategies separately. This difference of gender gap is not considered good and extremely unwelcomed by the marketers as efforts have to be raised by them. Some marketers believe that a common measure is good enough to handle the issue where as some feel it is workable to formulate separate strategy for both, Alreck \& Settle, (2001).

"Contemporary marketing has given due importance to gender which gives important insights of consumer, Caterall \& MacLaran, (2002).Taylor and Cosenza (2002) emphasized that generation Y have peculiar characteristics relating to their spending habits and also about their power to pester their parents to buy the products .Hence are considered as future consumers who are very important to the health of the marketing. A very interesting fact was revealed by them relating to their total spending, a major part is spend by them on apparels. Martin and Turley (2004) study described Gen Y as a "free spending but hard to reach generation." Mostly the members of this generation are working either full or part time and are considered as the wealthier members of the family.

To reach them is the biggest challenge faced by the marketer. Bakewell et al. (2006) made an interesting study 
which revealed that young generation (18-25years) generation $\mathrm{Y}$ have immense purchasing power and out of their total income they spend two-third on clothing. Euromonitor, (2007) In terms of spending on clothing, age is a stronger determinant of women's budget than their socio-economic status. The centre of this research is on clothing sector. Mintel, (2008) reported in his study that 20-24 and 25-34 age groups are of paramount magnitude to the marketers as women are less anxious about quality than style in their clothing. In order to discuss female or male shopping behaviour some main notions need to be clarified: The term sex is a genetic notion referring to whether a person is physiologically a man or a woman. It refers to psychologically, sociologically and culturally rooted behavioural propensities of men and women (Moss, 2009).A study analyzed the significance of demographic profile of consumers affecting the purchase decision of branded garments and to observe from gender perspective the consumer awareness about different apparel brands available in the Indian market and also to find out whether there is a significant difference in total expenditure on branded apparels done by males vis- a - vis females. The results exhibited no significant differences in the brand awareness, shopping frequency and shopping expenditure between males and females (N. Rajput, 2012).

From the above review of literature we can easily conclude that there are various studies which only focus on females buying behaviour in particular. This study is a modest attempt in this direction and aims to focus on female buying behaviour.

\section{Analysis and Interpretation of Results}

A good marketing strategy is that which has a deep understanding of its market insights. Sound communication, pricing, customer services and promotional policies can be successfully formulated and implemented with deeper knowledge and understanding of the market. Good strategy can only be formulated from deep understanding of behaviour of its customers and to formulate gender perspective policies, the behaviour patterns of males and females are very important to analyse.

\subsection{Do You Buy Branded Clothing?}

On asking the question as to purchase of branded apparels $75 \%$ of female respondents answered yes. This clearly exhibits the changing landscape of branded apparels in India and people are quite aware of the brand culture prevalent in India. This is the result of integrating India into the global economy and pursuance of liberalised regime which is responsible for changing the position of India as an investment centre with many players coming to India with their brands. Females in India are quite aware of all national and global brands and also about the positioning of the product see figure 1. Females are not buying products but are buying impacts and images which are coming from multinational culture, the fruit of globalisation.

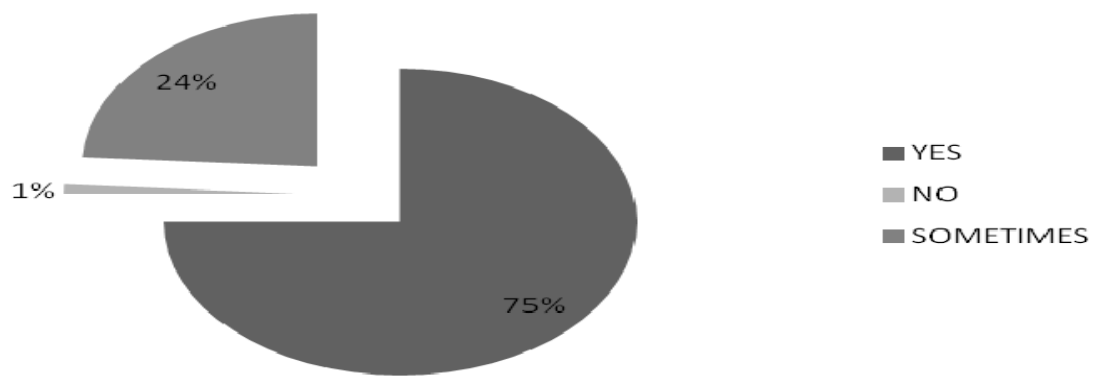

Figure 1. Do you buy branded clothing?

\subsection{How Frequently do You Shop for Branded Apparel?}

When the respondents were asked about the frequency of the branded apparels from the female respondents 57\% of them answered that they buy occasionally which is clear indication to the marketers that they have to put lot of efforts to change the frequency of the buying and transmit to frequent buying behaviour see figure 2 . Branded apparel market is exponentially growing but still is in its nascent stage where there are more challenges than opportunities which have to be handled tactically for the desired results. 


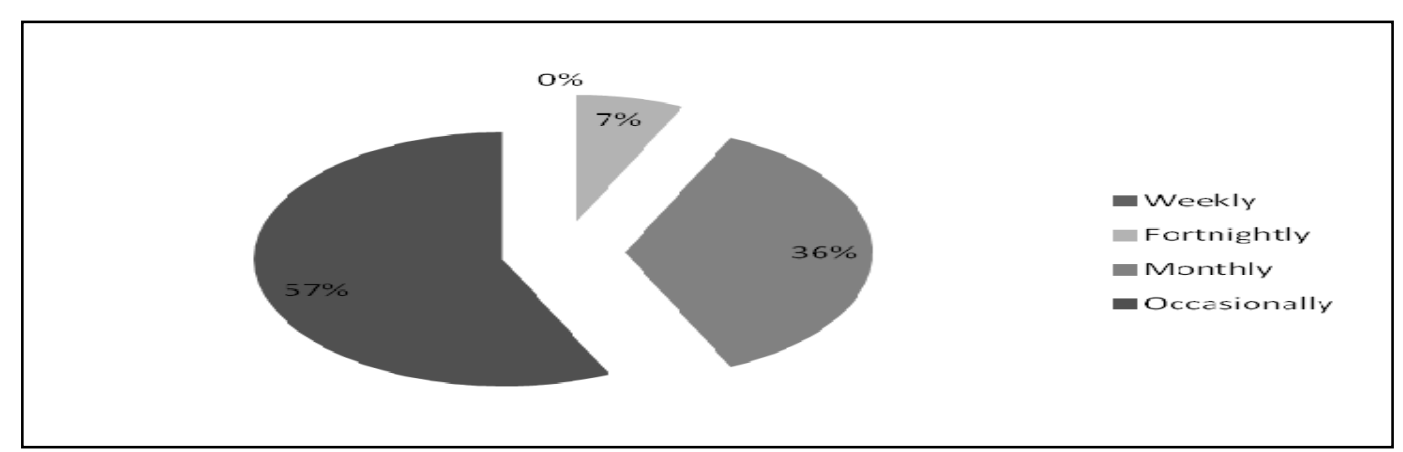

Figure 2. How frequently do you shop for branded apparel?

\subsection{Where do You Go for Shopping?}

On asking this question relating to place from where they shop about $45 \%$ said from mall, followed by super market as answered by $24 \%$, where as $17 \%$ and $14 \%$ from traditional shops and shopping websites etc see figure 3 . This answer gives us the insights relating to buying behaviour of females regarding mall mania and craze for shopping there because they get variety, style, fit, brands, reasonable price etc at one place. All the more the pleasure of shopping is enhanced because of cine- plex and eating joints, fast food chains like Mac- Donald's, KFC, Dominos, Pizza hut and other popular food chains. The motive behind buying behaviour is not just going to a retail showroom and buying, it is much more because of the factors mentioned above.

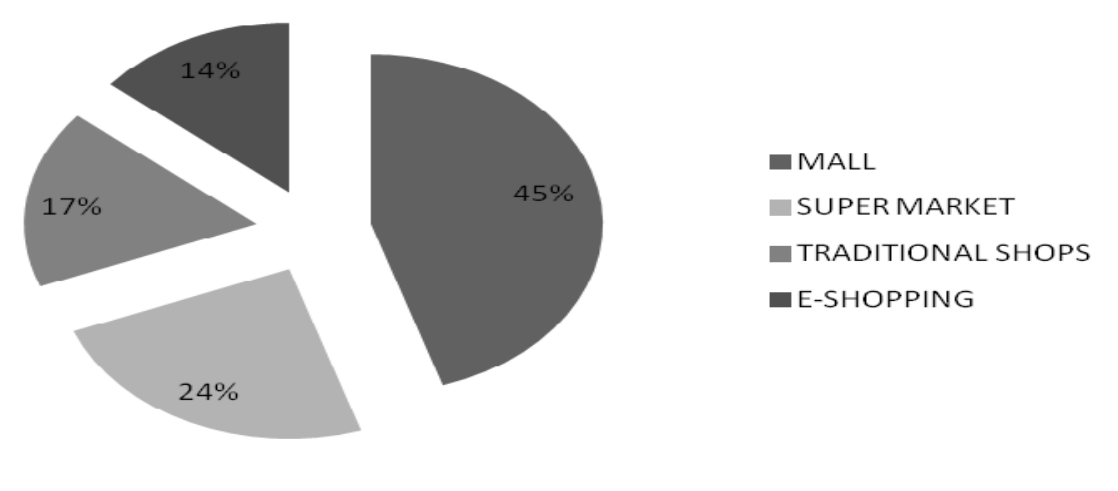

Figure 3. Where do you go for shopping?

3.4 What Are the Various Sources of Information Which Influence Your Buying Decisions?

To analyse the above mentioned question Confirmatory Factor Analysis was done. Standardised Regression weights were calculated using AMOS 18 . The results are exhibited below in Figure 4. 


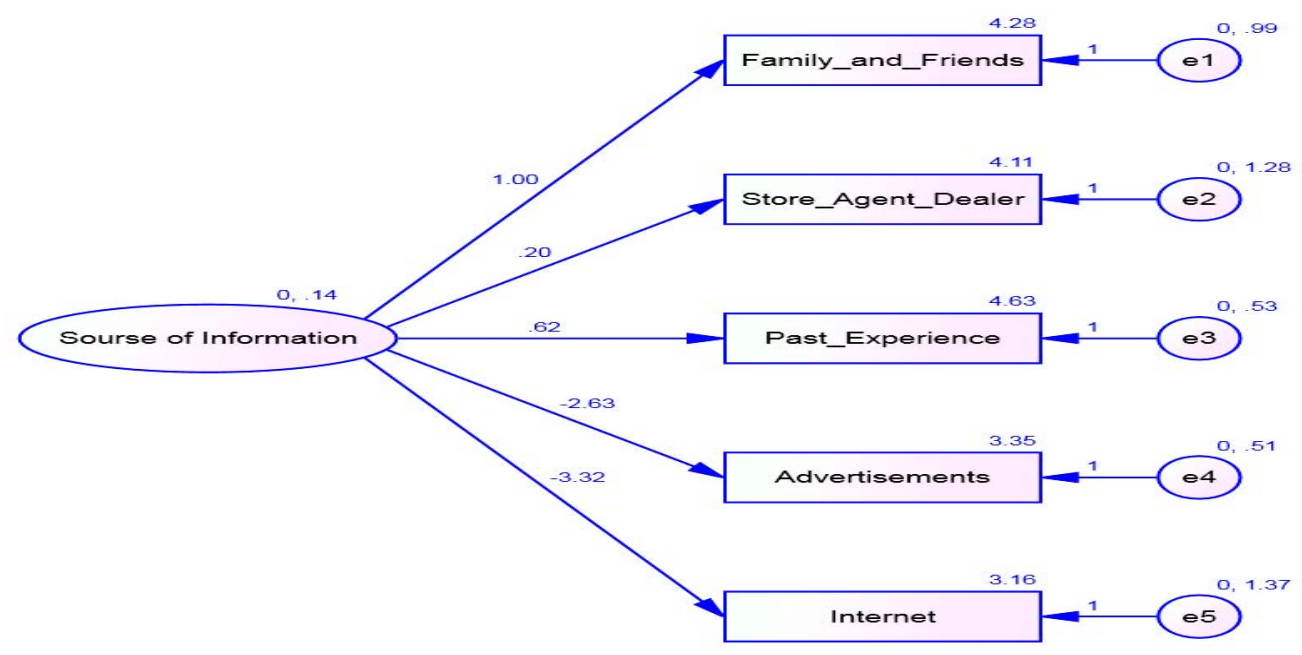

Figure 4. What are the various sources of information which influence your buying decisions?

Globalisation and increased competition, short product life cycle, increasing use of information and communication technologies has posed many challenges to the marketers to diligently develop core competencies in marketing strategies. Traditional sources are replaced by modern information technologies as is evident from the above figure.

The designed measurement model (as shown in figure 4) is helpful in explaining the contribution of various measured variables in explaining the sources of information which influence the Female buying behaviour. The standardized regression weights of each measured variable are shown in the table 1 . The standardized regression weights indicate comparative influence of the construct to its variables. The high value of the standardized weights indicates the higher influence of the construct to the variable. The results as shown in table 1 indicate that the most important source under source of information is family and friends which explains more than $70 \%$ of variation in the construct, followed by advertisement and Internet as significant factors in information gathering ,affecting the buying behaviour of consumer. Internet as an information source is very important nowadays in business as the level of competition; production processes and methods are rapidly increasing. It is of special importance in the field of marketing where companies keep an eagle eye on competitors and customers in order to keep pace with modern trends and analyze the needs, demands and desires of their customers.

The squared multiple correlations indicate the percentage of variance of the measured variable that can be explained with the help of the variations in the construct. As shown in the table 1, the squared multiple correlations of family and friends as an internet source is $49 \%$ percent of the variance of this measure can be explained with the help of sources of information construct. The squared multiple correlation of Advertisement indicates that 48 percent of the variance of the Advertisement can be explained with the help of variations in sources of Information followed by internet sources which explains $41.3 \%$ variation. Rest all sources are insignificant to explain the variation in the construct.

The statistics for goodness of fit of the model from AMOS output is shown in table 1 (A) the results indicate that the goodness of fit indices (CFI, RFI and NFI) is significantly high. Hence, the model is fit. The Chi-square value is also presented in the table. The lower value of RMSEA also supports that the model is fit. 
Table 1. Regression weights sources of information

\begin{tabular}{|c|c|c|c|c|c|c|}
\hline Name of the Variable & & & Estimate & $\begin{array}{c}\text { Standardised } \\
\text { Regression } \\
\text { Weight } \\
\end{array}$ & $\begin{array}{c}\text { Squared } \\
\text { Multiple } \\
\text { Correlation } \\
\end{array}$ & $\mathrm{P}$ \\
\hline Store_Agent_Dealer & $<--$ & \multirow{5}{*}{$\begin{array}{l}\text { Sources of } \\
\text { information }\end{array}$} & 1.000 & .472 & .223 & \\
\hline Family_and_Friends & $<--$ & & 2.406 & .700 & .490 & $0.00 *$ \\
\hline Past Experience & $<--$ & & .658 & .395 & .156 & 0.11 \\
\hline Advertisements & $<--$ & & .546 & .656 & .430 & $0.00 *$ \\
\hline Internet & $<--$ & & 1.388 & .643 & .413 & $0.00 *$ \\
\hline
\end{tabular}

Table 1(a). Model fit "sources of information"

\begin{tabular}{ll}
\hline Model Fit & Statistic \\
\hline Chi-square & 283.778 \\
CFI & .707 \\
NFI & .355 \\
RFI & .237 \\
RMSEA & .093 \\
LO 90 & .169 \\
HI 90 & .217 \\
\hline
\end{tabular}

\subsection{Relationship of Monthly Income and Frequency of Buying}

Relationship of monthly income and frequency of buying was tested using chi square test and was found to be significant. This is clear evidence that with the rise in the income of the consumer (females) there is a significant rise in the shopping frequency of the consumer as is exhibited i.e. higher the income higher the shopping frequency and vice-versa see

Table 2. Chi-square tests (relationship of income and shopping frequency)

\begin{tabular}{llll}
\hline & Value & Df & Asymp. Sig. (2-sided) \\
\hline Pearson Chi-Square & $20.966^{\mathrm{a}}$ & 9 & $\mathbf{. 0 0 3}^{*}$ \\
Likelihood Ratio & 24.188 & 9 & .004 \\
Linear-by-Linear & 4.318 & 1 & .038 \\
Association & & & \\
N of Valid Cases & 151 & & \\
\hline
\end{tabular}

\subsection{Relationship between Price of a Product and Buying a Branded Product (Apparels)}

Relationship between price of a product and buying of a branded product (apparels), was tested using Chi Square Test, the relationship was found to be significant. Females give prime importance to Price as a very important factor in the buying behaviour of branded apparels see, Table 3.

Table 3. Chi-square tests (relationship of buying branded products and price)

\begin{tabular}{llll}
\hline & Value & Df & Asymp. Sig. (2-sided) \\
\hline Pearson Chi-Square & $20.947^{\text {a }}$ & 8 & .007 \\
Likelihood Ratio & 17.957 & 8 & .022 \\
Linear-by-Linear & .013 & 1 & .908 \\
Association & 151 & & \\
N of Valid Cases & & & \\
\hline
\end{tabular}

\subsection{Relationship of Buying Branded Apparel and Status}

Relationship was tested to examine the relationship of buying of branded apparel because of status and was 
found to be insignificant as shown in Table 4. This means that there are other considerations in buying behaviour of females other than price which play a vital role in their buying decisions. These insights are very important in pricing and other core marketing policy formulation activities.

Table 4. Chi-square tests (relationship of buying behaviour of females and status)

\begin{tabular}{llll}
\hline & Value & Df & Asymp. Sig. (2-sided) \\
\hline Pearson Chi-Square & $7.152^{\mathrm{a}}$ & 8 & .520 \\
Likelihood Ratio & 8.067 & 8 & .427 \\
Linear-by-Linear & 1.999 & 1 & .157 \\
Association & & & \\
N of Valid Cases & 151 & & \\
\hline
\end{tabular}

\subsection{Do Celebrities Influence Your Purchase Decision of Apparels?}

There is a lot of awareness of brands because of use of Information and communication technologies that $69 \%$ of female respondents said NO, that their buying decisions are not influenced by any celebrity endorsement. There are many other factors which are responsible for her buying behaviour, only $18 \%$ of them said yes and $13 \%$ of them said sometimes see Figure 5. Mainly for those who have said yes there must be other factors like they were not having internet facilities or they are not computer friendly and only television is the medium available for them to know about the brands, hence celebrity endorsement plays an important role in buying decisions.

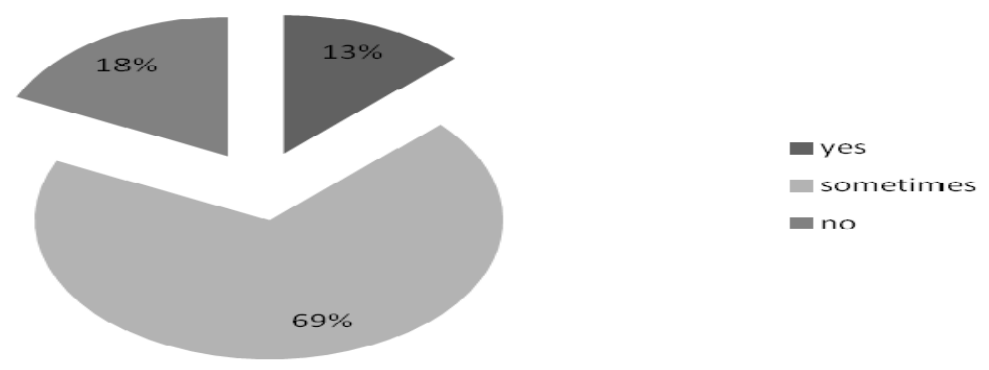

Figure 5. Do celebrities influence your purchase decision of apparels?

\subsection{Does Durability Attribute of Branded Apparels Affects the Buying Decisions?}

The relationship of durability attribute and buying of branded apparels were tested using chi square Test and was found to be insignificant. This means that durability and buying of branded apparels are not related and factors affecting female perspective in buying the branded apparels are not related to durability attribute see table 5 .

Table 5. Chi-square tests

\begin{tabular}{llll}
\hline & Value & Df & Asymp. Sig. (2-sided) \\
\hline Pearson Chi-Square & $8.468^{\mathrm{a}}$ & 8 & .389 \\
Likelihood Ratio & 7.429 & 8 & .491 \\
Linear-by-Linear & .218 & 1 & .640 \\
Association & & & \\
N of Valid Cases & 151 & & \\
\hline
\end{tabular}

\subsection{Does Fitting Is an Important Attribute in the Purchase of Branded Apparel?}

Relationship of fitting attribute and buying decisions of consumer was tested using Chi Square Test and found to be significant factor behind the purchase decision of female see Table 6 , for them fit of a branded garment is prime and their looks are enhanced after wearing that. This gives important signal to the marketer that due 
importance must be given to the fit factor as this is the most significant factor which is considered in their buying decision.

Table 6. Chi-square tests

\begin{tabular}{llll}
\hline & Value & Df & Asymp. Sig. (2-sided) \\
\hline Pearson Chi-Square & $41.652^{\mathrm{a}}$ & 8 & .000 \\
Likelihood Ratio & 18.777 & 8 & .016 \\
Linear-by-Linear & 2.071 & 1 & .150 \\
Association & 151 & & \\
N of Valid Cases & & & \\
\hline
\end{tabular}

\subsection{Does Style Is an Important Attribute in the Purchase of Branded Apparel?}

On testing the relationship mentioned above it was found to be insignificant in taking the buying decision. Style is an insignificant factor in influencing the buying decision see Table 7.

Table 7. Chi-square tests

\begin{tabular}{llll}
\hline & Value & Df & Asymp. Sig. (2-sided) \\
\hline Pearson Chi-Square & $10.909^{\mathrm{a}}$ & 8 & .207 \\
Likelihood Ratio & 11.601 & 8 & .170 \\
Linear-by-Linear & 1.010 & 1 & .315 \\
Association & 151 & & \\
N of Valid Cases & & & \\
\hline
\end{tabular}

\subsection{Relationship of Quality Attribute and Buying Branded Products}

The relationship of quality attribute and buying of branded products are tested .Chi Square Test was conducted to test the significance of the relationship and was found to be significant that is females will go extra miles to out shop for better quality of the product (branded apparel) see table 8.

Table 8. Chi-square tests

\begin{tabular}{llll}
\hline & Value & Df & Asymp. Sig. (2-sided) \\
\hline Pearson Chi-Square & $54.731^{\mathrm{a}}$ & 8 & .000 \\
Likelihood Ratio & 20.078 & 8 & .010 \\
Linear-by-Linear & 2.793 & 1 & .095 \\
Association & 151 & & \\
N of Valid Cases & & & \\
\hline
\end{tabular}

Quality attribute of the product is very important consideration in the buying decision of the branded apparel amongst females.

\section{Summary and Conclusions}

Consumer market for fashion apparel has become more varied by in surge of designer brands, store brands, personalisation, customs and advertisement in the global market place of today. From the above analysis it is clear that females have particular perspectives and motives behind their purchases. A clear understanding of preferences of consumers will help the marketer to attract and maintain their target consumer group. The present study conducted an investigation of attributes of shopping designer apparel among consumers in India mainly centric to urban females with a sample of about 150 females across diverse groups. The results are interesting and will give important insights to the marketer to redefine the strategies of retailing fashion apparel in India considering the global-local preferences. It was found in the study that there is a complete awareness of the 
branded apparels amongst females and their shopping behaviour reflect that they buy these products occasionally. The culture is shifting towards buying from the malls because of shopping experience the consumers get. The most important source of information was found to be family and friends followed by internet and advertisement. It is observed in the study that Price, Fitting, Income Level of consumers are significant factors and females have distinctive appeal for these factors in distinctive apparel shopping behaviour and should be considered seriously by apparel retailers in strategy formulation while giving critical importance to these factors. There are some factors which are found to be insignificant like Status, Durability, and celebrity endorsement, hence can be ignored by the apparel retailers in their efforts to tap and capture the market. As a retailer of apparels, all these insights have to be embedded in the policy formulation to make the purchases a real time customer delight .Retailers have to unleash the basket of pleasure so as to expand, sustain and maintain the market share.

\section{References}

Alreck, P. L., \& R. B. Settle. (2001). Consumer Attitudes toward Returning Goods. Global Business Trends Contemporary Readings, Academy of Business Administration.

Bhardwaj, V., \& Fairhurst, A. (2010). Fast fashion: response to changes in the fashion industry. The International Review of Retail, Distribution and Consumer Research, 20, 165-173. http://dx.doi.org/10.1080/09593960903498300

Cassill, N. L., \& Drake, Mf. (1987). Apparel selection criteria related to female consumers' lifestyle. Clothing and Textiles Research Journal, 6(1), 20-28. http://dx.doi.org/10.1177/0887302X8700600104

Easey, M. (ed.). (2009). Fashion marketing (3rd ed.). Oxford: Wiley-Blackwell.

Fischer, E., \& Arnold, S. J. (1994). Sex, gender identity, gender role attitudes, and consumer behavior. Psychol. Mark., 11, 163-182. http://dx.doi.org/10.1002/mar.4220110206

Huddleston, P., \& Cassill, N. L. (1990). Female consumers' brand orientation: the influence of quality and

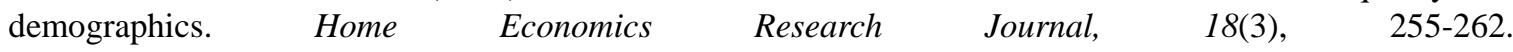
http://dx.doi.org/10.1177/1077727X9001800307

Johnson, L., \& Learned, A. (2004). Don't think pink: what really makes women buy-and how to increase your share of this crucial market. New York: amacom.

MARTIN, C. A., \& TURLEY, L. W. (2004). Malls and consumption motivation: an exploratory examination of older generation Y consumers. International Journal of Retail \& Distribution Management, 32(10), 464 475. http://dx.doi.org/10.1108/09590550410558608

Mintel. (2008). Women swear - UK - March 2008.

Rajput, N. et al. (2012). Consumer attitude towards branded Apparel: gender perspective. International Journal of Marketing Studies, 4(2). http://dx.doi.org/10.5539/ijms.v4n2p111

Rutter, N., \& Edwards, O. (1999). Ready to Ware. Forbes, 163(7), 30-33.

Schiffman, Leon G., \& Kanuk, Leslie Lazar. (2005). Consumer Behaviour. Prentice Hall of India.

Taylor, S. L., \& Cosenza, R. M. (2002). Profiling later aged female teens: mall shopping behaviour and clothing choice. Journal of Consumer Marketing, 19(5), 393 - 408. http://dx.doi.org/10.1108/07363760210437623

Thomson, C. J., Pollio, H. R., \& Locander, W. B. (1994). The Spoken and Unspoken. Journal of Consumer Research, 21(3), 432-452.

Tungate, M. (2008). Fashion brands: branding style from Armani to Zara (2nd ed.). London: Kogan Page. 